\title{
Novos roteiros intrapsíquicos versus permanências culturais: possíveis limites de uma sexualidade informada
}

\section{| ${ }^{1}$ Bruno José Barcellos Fontanella, ${ }^{2}$ Romeu Gomes |}

Resumo: Objetivou-se analisar os sentidos atribuídos por homens jovens à sexualidade masculina e a suas práticas sexuais, visando compreender eventuais dificuldades em aderir a práticas preventivas em relação à Aids. Ancorada na teoria dos roteiros sexuais e no conceito de habitus, foi realizada uma análise de enunciação sobre um acervo de 42 narrativas, provenientes de suas subamostras de jovens diferenciados em relação à escolaridade e estrato socioeconômico. Dois conflitos parecem influenciar de modo determinante as práticas sexuais preventivas dos participantes. De um lado, elementos cognitivos de uma "sexualidade informada" se opõem à dimensão do prazer relacionado às práticas sexuais. De outro lado, tais elementos informativos se contrapõem aos componentes psicoculturais mais estáveis relacionados ao habitus masculino. A base empírica sobre a qual se trabalhou permite um aprofundamento da compreensão das nítidas limitações de efetividade das iniciativas de prevenção em saúde baseadas em informações sobre práticas sexuais de risco.

> Palavras-chave: gênero e saúde; sexualidade; identidade de gênero; narrativa; pesquisa qualitativa
1 Universidade Federal de São Carlos. Endereço eletrônico: bruno.fontanella@gmail.com

2 Pesquisador titular do Departamento de Ensino do Instituto Fernandes Figueira da Fiocruz. Endereço eletrônico: romeugo@gmail.com 
Este estudo objetiva analisar os sentidos atribuídos por homens jovens à sexualidade masculina e à prevenção da Aids. Partiu-se da premissa de que esses sentidos são influenciados por complexos fatores psicossocioculturais que servem de referência para a elaboração de discursos sobre a sexualidade e os cuidados preventivos.

A emergência da epidemia de Aids na década de 80 levou não apenas à alteração dos modelos sociológicos de compreensão do processo saúde-doença, como também possibilitou modos inéditos de interação entre os sujeitos e as políticas de saúde (HERZLICH, 2004; BURY, 2001; HYDÉN, 1997). Em razão dos modos de contágio, a epidemia também alterou, em escala mundial, como as pessoas vivenciam e desempenham determinados papéis sociais, e, sobretudo, como compreendem e praticam suas sexualidades (BOZON, 2009).

No Brasil, os poderes públicos têm marcado esse processo histórico por meio de estratégias contundentes em diferentes níveis preventivos, incluindo a educação em saúde sexual. As campanhas públicas visando incentivar o uso do preservativo pelos jovens em suas relações sexuais compóem o conjunto dessas táticas de promoção à saúde e prevenção primária.

Focaliza-se aqui uma campanha empreendida por ocasião do carnaval de 2008 e do "Dia Mundial de Luta contra a Aids" de 2007. Seu mote foi a pergunta "Qual é a sua atitude na luta contra a Aids?”, dirigida à faixa etária dos 14 aos 24 anos, e que intencionava afirmar direitos do jovem de "viver sua sexualidade e de ter acesso ao preservativo e à informação", visando somar "esforços para munir a juventude dos conceitos de prevenção" (BRASIL, 2007). Esse empreendimento convidava os jovens a refletirem sobre suas atitudes, o que levou à formulação da seguinte questão de pesquisa: podendo responder à questão-mote da campanha, que elementos os jovens poderiam fornecer para aprofundar a compreensão de suas eventuais dificuldades em aderir às práticas sexuais preventivas?

Dada a gama de análises suscitadas, são apresentados e discutidos aqui apenas os resultados relativos aos sentidos atribuidos às informações sobre saúde sexual.

\section{Marcos teóricos: habitus e roteirização sexual}

Dois marcos teórico-conceituais são utilizados: roteiros sexuais (GAGNON, 2006; BOZON, 2009) e habitus (BOURDIEU, 2002; 2007; PINTO, 2000). 
Pelo conceito de habitus, cunhado por Bourdieu, entende-se um conhecimento adquirido, um "haver", indicando uma disposição incorporada. Social e historicamente construído, possibilita às pessoas pensar, ver e agir frente às variadas situaçóes. Diferentemente da palavra hábito, que se associa a algo cristalizado, o habitus envolve uma capacidade inventiva e, nesse sentido, possibilita tanto a regularidade de certos comportamentos como a possibilidade de improvisação criativa por parte dos agentes sociais. Em outras palavras, trata-se de uma espécie de gramática gerativa de práticas, fazendo com que os agentes não só as reproduzam, mas também percebam, classifiquem e avaliem seus costumes e práticas. O habitus não só interioriza o exterior, como também exterioriza o interior, ou seja, é ao mesmo tempo estruturado a partir de determinadas condições anteriores a ele e estruturador de novas condições para que se possa lidar com situações percebidas como desajustadoras (PINTO, 2000).

Já os roteiros sexuais são concebidos como um conjunto de elementos simbólicos verbais e não verbais ligados à sexualidade, e que estruturam uma sequência de condutas organizadas e delimitadas no tempo, nomeando os atores dessas condutas, descrevendo suas qualidades, indicando motivos dos comportamentos e encaminhando-os a finalizaçōes exitosas (GAGNON, 2006). Esses roteiros são construídos a partir das experiências sexuais apreendidas e inscritas na consciência, formando scripts para se lidar com a sexualidade possível (BOZON, 2009). Eles podem ser de três ordens: intrapsíquico (dimensão subjetiva), interpessoal (dimensão das interaçōes sociossexuais) e cultural (dimensão dos cenários e de prescriçōes culturais).

Contemporâneos, John Gagnon e Pierre Bourdieu não se referenciaram mutuamente. Entende-se, porém, que o conceito de roteiro cultural dialoga proximamente com o de habitus. Ambos compartilham as características de serem dinâmicos (pois estão continuamente sendo estruturados) e simultaneamente apresentam constâncias (o que lhes permite estruturar a vida sociocultural). A noção de habitus porém, está mais próxima da de potencial cultural, responsável por regularidades de aspectos da vida social ao longo do tempo e, por esse aspecto de maior estabilidade, o conceito de habitus confunde-se com o de identidades sociopsicológicas. Os roteiros culturais, por sua vez, correspondem a configurações mais distinguíveis e operacionalizáveis (à medida que se transpõem em desempenhos observáveis) de arranjos de representações e expectativas que norteiam e dirigem de maneira mais imediata certos comportamentos. 
Ao se considerar habitus e roteiros referentes a uma mesma esfera de fenômenos sociais (no presente caso, habitus masculino e roteiros sexuais de jovens do sexo masculino), os roteiros sexuais intrapsíquico e interpessoal se situam numa esfera de maior volatilidade, de menores permanências, ao passo que o roteiro cultural e o habitus estão mais próximos de um núcleo sociocultural mais resistente a mudanças. A eficácia de medidas preventivas para DST/Aids depende, em última instância, de mudanças comportamentais de indivíduos inseridos culturalmente. Sendo assim, entende-se que as noções de roteiros sexuais e de habitus masculino configuram-se, ambos, como ferramentas intepretativas úteis à compreensão de seus limites.

O estudo, realizado na cidade do Rio de Janeiro, Brasil, é parte de uma investigação cujo objetivo geral era analisar os sentidos atribuídos por homens à sexualidade masculina e aos cuidados de saúde no campo da sexualidade. A pesquisa foi aprovada pelo Comitê de Ética em Pesquisa do Instituto a que os autores estão vinculados.

\section{Metodologia}

Foi aplicada uma abordagem metodológica qualitativa (DENZIN; LINCOLN, 2000), visando interpretar um conjunto de narrativas de jovens do sexo masculino. As entrevistas narrativas são uma técnica de coleta de dados que procura "reconstruir acontecimentos sociais a partir da perspectiva dos informantes", sendo as ações e o contexto narrados elementos que mostram "o lugar, o tempo, a motivação e as orientações do sistema simbólico do ator" (JOVCHELOVITCH; BAUER, 2002, p.92-93). Foram coletadas a partir do disparador representado pelo slogan da campanha, apresentado a todos os participantes nos mesmos termos: "Qual é a sua atitude na luta contra a Aids?". A coleta de dados se processou no primeiro semestre de 2009 por entrevistadores de mesmo sexo e faixa etária dos entrevistados e com formação em ciências humanas.

A amostra da pesquisa considerou os sujeitos em número suficiente para que houvesse reincidência e saturação de sentidos (MINAYO, 2007; FONTANELLA; RICAS; TURATO, 2008) e levou em conta a possibilidade de inclusões sucessivas de sujeitos as quais viabilizassem uma discussão teoricamente densa. Adotouse a estratégia de amostragem de "universos familiares" (VAITSMAN, 1994; VELHO, 1981), na qual pessoas conhecidas do pesquisador indicam outras para participarem da pesquisa, que, por sua vez, indicam outros possíveis participantes. 
Os sujeitos do estudo foram homens jovens que, nascidos numa mesma época, teriam experimentado acontecimentos sociais comuns, compondo uma mesma geração (DOMINGUES, 2002). Foram selecionados jovens nascidos aproximadamente na segunda metade da década de 1980, com idade à época da entrevista entre 18 e 25 anos, e que começaram o período de iniciação sexual no final dos anos 90. Esse período foi escolhido porque compôs o cenário de várias campanhas de prevenção da Aids.

Procurou-se trabalhar com dois grupos: um de homens jovens que cursavam o ensino superior (Grupo I) e outro com os que não o cursavam e residiam numa comunidade de classe popular (Grupo II). Com esses grupos, pretendia-se verificar se os sentidos atribuídos aos cuidados de saúde quanto à sexualidade masculina se diferenciavam entre jovens com escolaridades e classes socioeconômicas distintas.

Para contextualizar as narrativas, foram coletados dados sociodemográficos e algumas informações objetivas acerca de suas experiências sexuais (tabelas 1 e 2).

Tabela 1. Informações sociodemográficas referentes aos elementos pesquisados das duas subamostras

\begin{tabular}{l|c|c}
\hline $\begin{array}{c}\text { Características } \\
\text { sociodemográficas }\end{array}$ & Grupo I (n=22) (\%) & Grupo II (n=20) (\%) \\
\hline Idade (anos) & 0 & 20 \\
18 & 0 & 35 \\
19 & 0 & 0 \\
20 & 5 & 5 \\
21 & 45 & 10 \\
22 & 45 & 15 \\
23 & 5 & 10 \\
24 & 0 & 5 \\
25 & & \\
\hline Cor autorreferida & 64 & 40 \\
Branca & 18 & 45 \\
Parda & 18 & 15 \\
Preta & 0 & 0 \\
Amarela e indígena & & \\
\hline Ocupação trabalhista & 68 & 35 \\
Sim & 32 & 65 \\
Não & & \\
\hline
\end{tabular}

*Salário mínimo à época das entrevistas $=\mathrm{R} \$ 415,00$ 
Tabela 2. Informações sobre sexualidade sociodemográficas referentes aos elementos pesquisados das duas subamostras

\begin{tabular}{l|c|c}
\hline \multicolumn{1}{c|}{ Informações } & Grupo I (n=22) (\%) & Grupo II (n=20) (\%) \\
\hline $\mathbf{1}^{\text {a }}$ relação sexual planejada & 18 & 32 \\
Sim (= não incidental) & 73 & 68 \\
Não (= incidental) & 9 & 0 \\
Não informou & & \\
\hline Uso de preservativo na 1a relação & 86 & 47 \\
sexual & 9 & 53 \\
Sim & 5 & 0 \\
Não & & 60 \\
Não informou & 32 & 35 \\
\hline Uso de preservativo na última & 64 & 5 \\
relação sexual & 4 & \\
Sim & & \\
Não & & \\
Não informou & & \\
\hline
\end{tabular}

Posteriormente à transcrição integral, as narrativas foram analisadas e interpretadas a partir de uma adaptação da técnica de análise de enunciação (BARDIN, 1979; MINAYO, 2007). As proposições nelas contidas não foram tomadas como dados fracionados e manejáveis (ou seja, como temas, simplesmente), mas como partes de um processo comunicativo dinâmico de elaboração de sentidos e de transformação destes em palavras e frases. Nessa transformação, considerou-se haver um trabalho de elaboração das opiniōes, representações e atitudes, em que podiam também atuar constrangimentos (frente, por exemplo, ao entrevistador) e resistências psicológicas diante de conflitos internos suscitados pelos temas abordados.

Depois de uma familiarização com os enunciados, e ancorados nos marcos teórico-conceituais referidos, os achados foram circunscritos em categorias, de acordo com a identificação de núcleos de sentido relativos à prevenção da Aids. Procurou-se manter uma postura de atenção aos pormenores e ao acervo como um todo, em busca da validade interna dos achados, ou seja, da presença de uma consistência empírica que subsidiasse a discussão teórica. 


\title{
Caracterização dos sujeitos
}

Foi formado um acervo de 42 narrativas, sendo 22 de homens jovens que cursavam o ensino superior (Grupo I, com nomes fictícios iniciados por S) e 20 com homens jovens que não cursavam o ensino superior e que residiam numa comunidade de classe popular (Grupo II, com nomes fictícios iniciados pela letra $\mathrm{R})$. Os jovens dos dois grupos apresentaram, em geral, características distintas (tabela 1), de acordo com a estratégia de obter uma amostra heterogênea quanto à escolaridade e classe socioeconômica.

Em relação às informações sobre planejamento da primeira relação sexual (se incidental ou não) e uso de preservativo, os grupos apresentaram semelhanças e diferenças (tabela 2). Chama a atenção que os jovens do grupo I, embora tenham usado o preservativo na primeira relação, em geral informaram que não o fizeram na última. Apesar dessas informaçôes apontarem diferenças entre os grupos, as narrativas apresentaram várias homologias, como será destacado adiante.

\section{Resultados}

Cinco categorias analíticas foram fundamentadas empiricamente e subsidiarão a discussão. As fronteiras entre elas nem sempre são nítidas, servindo antes à demarcação de certas dimensōes que se complementam na abordagem do conjunto dos dados.

\section{"É muito complexo" ou "não ter nada para falar"}

As falas dos entrevistados sugeriram que a sexualidade não é assunto sobre o qual discorrem facilmente, principalmente quando o tema é a própria sexualidade. Para o grupo I, sobretudo, o sentido inicial preponderante associado à sexualidade foi de complexidade:

\author{
Falar de sexo, sexualidade, é meio complicado. [Sinval] \\ Complexo! [Sócrates]
}

Nos relatos dos jovens do grupo II, as dificuldades mais chamativas nesse mesmo sentido pareceram decorrer de eles sentirem ter poucos instrumentos cognitivos (conceitos, informaçôes) para pensar sobre o tema:

Muito interessante [a questão da pesquisa], apesar de que quase eu não entendi nada." [Ronald] 
Nos dois grupos, foi sugerida uma diferença de gênero, pois apontou-se para uma maior dificuldade dos homens em falar sobre a sexualidade. Ao final dos relatos, houve demonstrações de alívio por se ter passado pela prova representada por ter de expressar-se sobre o tema:

Falar de sexualidade é a coisa mais complicada pro homem. [Sálvio]

Pro homem, falar sobre sexualidade é meio complicado. [...] Já falei demais, já falei muito, mais do que tô acostumado. [Rivaldo]

\section{"Todo mundo tem que se cuidar"}

Apesar desses entraves, a sexualidade foi constantemente referida como algo a ser pensado. Os sujeitos tenderam a enfatizar a importância de se falar a seu respeito: deve-se pensar sobre ela e também inserir o tema num fluxo de comunicação cotidiana:

Falar de sexo é importante, quebrar essa barreira. Falar de sexo é um tabu. [Samir]

Ambos os grupos utilizaram, de maneira chamativa, um discurso fortemente prescritivo sobre como se deve exercer e praticar a sexualidade, quanto aos cuidados a serem tomados. A expressão "tem que" foi repetida seguidamente em praticamente todas as 42 entrevistas. Tais preceitos dirigiram-se tanto a si mesmos (cuidar-se), quanto às suas parceiras, como também àquilo que parecem considerar dever ser a ordem social na esfera sexual, com uma forte ênfase numa sexualidade preventiva, a ser obedecida e assegurada:

As pessoas têm que se proteger [...]. Eu, nas minhas relações, sempre procuro proteger a mim e a minha namorada. [Radamés]

Tem que tá limpo, tem que tomar banho, tem que se prevenir na hora, sempre também aconselhar os outros a se prevenir [...]. [Reis]

São cuidados que tem que saber, que é a questão do uso de preservativo, escolha de parceiros regulares e não... sexualmente ativa com vários parceiros não conhecidos. [Sandro]

Acho que também o homem tem que ter cuidado. [Sebastião]

Nos relatos do grupo II, essa ordem social de cunho preventivo teria o sentido de garantir maior coesão social, algo como manter cuidados constantes para que o sistema social funcione:

Se você não aconselhar os outros a se prevenir, você também está se autodescuidando, que a sociedade tá todo mundo, a gente em si, unida, assim, se esbarrando. [Reis] 
A ideia de "cuidados sexuais" estaria fortemente inserida na perspectiva dos sujeitos, que previram incluir em seus desempenhos o uso do preservativo, como também advogam pelo emprego de várias modalidades de atenção a problemas corporais (um "cuidado profissional médico constante", segundo um entrevistado).

Ao chegar às relações interpessoais, identificou-se uma relativização do que esses cuidados objetivam. Para as parcerias sexuais consideradas "fixas" (em contraposição às parcerias eventuais, "não fixas"), a prevenção de gravidez indesejada é enfaticamente prescrita, porém os cuidados para prevenir DST são mitigados ou interrompidos:

Com a parceira fixa, algumas vezes, se não muitas vezes, você acaba deixando isso um pouco de lado [...] e não é por falta de alcance ou de informação que eu faça isso. [Saulo]

\section{“Temos a informação na nossa mão e temos que usá-la”}

Para os participantes, suas práticas sexuais requerem informações seguras e confiáveis, valorizando esses subsídios para balizar seus planos de ação:

É fácil ter acesso às informações e utensílios ... a mecanismos de prevenção ... tem que aproveitar que estamos numa época de avanços tecnológicos e também dos meios de comunicação e se aproveitar disso. [Solano]

Quanto ao "acesso às informaçōes", identificou-se uma assimetria entre os dois grupos. Para o grupo I, as informações seguras devem vir de fontes cientificamente validadas, havendo uma demanda por um padrão científico de conhecimentos para subsidiar "o que pode" ser feito nas práticas sexuais:

Apesar da campanha ... ainda assim, DST é [...] uma coisa obscura, uma coisa de difícil acesso [para a 'camada baixa' da população]. Às vezes, é difícil ter acesso, apesar de [eles] terem internet, a uma informação segura. [Samuel]

Ainda quanto ao acesso e ao uso que se faz da informação, houve referências do grupo à concomitância de duas subculturas distintas: uma considerada mais tradicional (e com a qual se deve ter "muito cuidado ao lidar") e outra, informada, à qual esses jovens universitários sentem pertencer. A lógica do cuidarse sexualmente de uma maneira informada parece se arraigar em suas visões e gerar a percepção de um contraste entre os dois padrões subculturais (valorização versus não valorização da informação). Houve, de fato, enunciados sugestivos de uma postura etnocêntrica, não compreensiva, em relação a padrões alheios:

Ser macho é o cara que faz filho a rodo ... são culturas que tem que quebrar ... muito cuidado ao lidar com essas culturas. Somos uma geração da internet, televisão, jornais, 
você tem acesso a todo grau de informação ... geração que temos a informação na nossa mão e temos que usá-la. [Samir]

Antiquada, ignorante ... a informação tá ali, mas... [Sinclair]

Tal estranheza etnocêntrica foi explicitada na forma de se referirem aos outros ("eles", "o pessoal") que não adotam o padrão informado de cuidados. Desse padrão faria parte "nomear", "falar abertamente", procurar diretrizes científicas de como se comportar, bem como "admitir que precisa se informar":

A pessoa não nomeia, não falam assim muito aberto, não quer admitir que precisa se informar. [...] Não sabe o que devia ter feito [...] o pessoal não tem informação, até mesmo sobre cuidados, o que tem que fazer diariamente. [Sebastião]

A valorização do informar-se refere-se às intençôes e prescriçôes individuais e chega também às relações interpessoais, a como efetivamente se procura atuar nessas relaçōes. As informações buscadas determinariam, na prática cotidiana, o que se considera "poder" ou "não poder" fazer:

Se informar, principalmente, se informar sobre doenças, sobre o que é normal, o que não é normal, o que pode, o que não pode fazer. [Sérgio]

\section{"Sempre tenho tentado entender"}

No grupo II, houve igualmente valorização de informações para subsidiar práticas sexuais, chamando a atenção, no entanto, as dificuldades aparentemente maiores para lidar com a lógica e os conceitos biomédicos que subjazem às práticas preventivas. Alguns entrevistados expressaram conceitos um tanto confusos e comentaram ter constantes práticas autodidáticas para sobrepujar dificuldades e se aproximar dos conhecimentos científicos:

$\mathrm{Na}$ verdade fico muito tempo na internet, tô sempre lendo sobre esses assuntos [...] sobre as doenças, as infecções, essas coisas todas [...] sempre tenho também tentado entender. [Randal]

Quando você tá transando, a pele mesmo, antes de você ejacular, sai um líquido que inibe o pênis pra abrir o caminho. Acho que só aquilo ali já basta, o espermatozóide ir no caminho dele. Não sabia disso [...] vi isso no programa [de tv], aí comecei a me ligar no assunto da sexologia, aí me liguei e falei: caraca, nem sabia dessa parte. [Rivo]

As patologias, particularmente, exigiriam um nível de abstração difícil para alguns, o que foi sugerido nas seguintes frases, nas quais há mençôes aos que detêm os conhecimentos ("os médicos", "os outros") e aos que não detêm: 
Paga pra ver, não acreditando no que os outros falam. [Rufino]

Apesar dessas dificuldades, os entrevistados do grupo II também fizeram alguns contrapontos desqualificativos a fontes duvidosas de informações. Um deles chamou a atenção para fontes boas e más: a fonte boa é a institucional, tendo o participante expressado rechaço à troca informal de informações:

Jovem confunde muito [...] Às vezes muita gente é mal informado, a cabeça do "disse me disse": "não sei quem me disse que é assim, assim, assado". [...] Muita gente vai pela cabeça dos outros. [Reginaldo]

A busca de informações - a despeito das supostas dificuldades cognitivas para assimilá-las - dar-se-ia de maneira angustiada para alguns participantes. O exercício de suas sexualidades estaria emoldurado pela premência de conhecer as doenças, contrastando com as raras mençôes a ideias de prazer e desejo sexual (embora nesse grupo isso pareça acontecer mais do que no grupo I). Conhecer como as doenças são transmitidas é sentir-se fazendo "tudo certinho":

Usei camisinha, mas acho que se soubesse mais o que poderia acontecer, qual o risco que poderia correr ... tivesse uma consciência melhor. [...] conhecia bem o que era, DST e tal, como é que pegava, a doença então, tudo certinho. [Ramon]

Procurar entender exatamente ... os processos de se adquirir doenças, como se tratar, entender toda a situação, não só com relação à Aids, também com outros tipos de doenças. [Randal]

Houve também referências à tradução de conhecimentos pelos profissionais de saúde, e sugeriu-se maior veiculação visual de informações:

[...] Tá passando esta informação pros casais, assim, inexperientes. [...] os médicos teriam que passar para a população [sobre virologia do HIV]. [Reinaldo]

Não tem um cartaz, na rua não tem nada [...] não tem um evento[ ...]. pras pessoas verem que é aquilo. [Roger]

\section{"A gente amadurece, então eu sei o que eu tô fazendo"}

Os mesmos jovens do grupo II proferiram, por outro lado, enunciados que valorizaram a "maturidade" e a "experiência" que se pode adquirir com tempo, atributos que adviriam naturalmente ao longo do ciclo vital:

Quando for ter filho, vai ganhar experiência [de vida]. [Rivelino]

Dezessete anos, entendeu? A gente não tem muita cabeça ainda. [Rivo] 
Até porque sou maior de idade, tenho que saber respeitar. [Romário]

Tem outros aí que não quer saber não, novinho, não quer saber de nada, novinho descontrolado. [Rufino]

Maturidade e experiência parecem, nesse caso, fazer uma contraposição com o aprendizado formal: um homem mais experiente, contanto que confiável, próximo e disponível, poderia orientar o mais inexperiente, e o ambiente familiar, em alguns casos, facilitaria esses diálogos:

Gosto de me aprofundar nisso com pessoas próximas. [Rômulo]

Seria uma pessoa conhecida e com mais experiência, e também uma pessoa que eu confie. Aí eu chamava o cara e conversava pra ver qual era a opinião dele. [Romualdo]

A gente amadurece [...] Já tenho uma mente legal, já sou adulto, então sei o que tô fazendo. Às vezes alguém da minha família ou um amigo meu vai me dá um toque [...] eu paro, assimilo que tavam falando para mim, porque é bom a gente escutar, a gente escutando, a gente aprende. [Rodrigo]

No caso das referências à troca de conhecimentos dentro da família, o sexo do interlocutor não pareceu ser valorizado, mas sim sua experiência. Valorizou-se sobretudo o status de pai ou mãe como bons transmissores de valores:

Me deu um esclarecimento maior que o homem tem que fazer [...] a gente aprende simplesmente ... minha mãe fez esse papel e me explicou tudo muito direitinho. [Ramon]

Os pais da menina também, que sempre me deram maior apoio no negócio de doença, essas coisas. Foi através deles, assim, que me passou as informações. [Rafael]

Aparentemente, esse tipo de fonte mais informal de conhecimentos se associa mais a um aprendizado na dimensão atitudinal/afetiva do que na cognitiva, dando alguns sujeitos uma ênfase maior às questôes morais do que ao "saber". Perceberiam pressões, na rede de relaçôes sociais, mais por "atitudes corretas" e menos por um convencimento por meio de informações:

A gente fica mais maduro pra pensar nas coisas, o que fazer, antes de fazer. [...] Pensar bastante o que vai fazer e antes de fazer, e depois que fizer não tem como voltar atrás. [Robson]

Várias pessoas que me deram muitas opinióes [...] acabei mudando a minha opinião, agora que já tenho mais mentalidade. [Rafael]

Ocorreria também uma troca de relatos de experiências com conhecidos do sexo masculino, com acréscimo de repertório progressivo:

Com o homem é mais máfia de você falar, você tem aquela intimidade. [Rômulo] 
Tendo sido identificada essa ênfase em maturidade e na troca de experiências

pessoais nos relatos do grupo II, elas foram também procuradas ativamente nas falas dos sujeitos do grupo I e não foram encontradas.

\section{Discussão}

Os jovens entrevistados pertencem a uma geração que nasceu durante a irrupção da epidemia de Aids, tornando-se alvo de esforços oficiais que visaram influenciar seus comportamentos para o uso do preservativo, o qual foram instados a conhecer e adotar em todas as relações sexuais.

No Brasil e em outros países, os empreendimentos em educação sobre saúde sexual surtiram efeitos, havendo uma progressiva incorporação da utilização do preservativo masculino nas sucessivas coortes (BERQUÓ; BARBOSA; LIMA, 2008), principalmente nos primeiros anos da fase de iniciação sexual juvenil e, sobretudo, entre os mais escolarizados (BOZON, 2009; BERQUÓ; BARBOSA; LIMA, 2008). Entretanto, já se constatou que a frequência do uso consistente do preservativo (isto é, em todas as relações sexuais) diminui nos anos seguintes a essa primeira etapa iniciatória (BOZON, 2009).

Isso parece ocorrer à medida que o jovem passa a ter mais idade (TRAJMAN et al., 2003), maior experiência sexual e relações que eles consideram mais estáveis (BERQUÓ; BARBOSA; LIMA, 2008; CAMARGO; BOTELHO, 2007). Esses fenômenos remetem à discussão da relação entre informação sobre sexo seguro (na esfera dos roteiros sexuais intrapsíquicos) e a efetiva prática sexual (na esfera dos roteiros interpessoais). Estudos brasileiros já mostraram reiteradas vezes a seguinte incongruência: ter conhecimentos satisfatórios sobre comportamentos de risco não leva, necessariamente, ao uso constante e consistente do preservativo masculino (FERNANDES, 1998; ANTUNES et al., 1997; PINTO et al., 1994).

$\mathrm{Na}$ presente pesquisa, esses fenômenos foram evidenciados nos relatos individuais dos entrevistados, dando a oportunidade de tentar compreender tal incongruência. Constatou-se uma contraposição que parece ser fundamental. Por um lado, os participantes apontaram claramente uma intensa valorização de informações para subsidiar as opiniōes, decisões e os comportamentos sexuais, tanto sobre contracepção quanto sobre DST/Aids. Tal valorização se deu na forma de conteúdos explicitados nas falas, compondo, portanto, seus roteiros sexuais intrapsíquicos (GAGNON, 2006; BOZON, 2009). Ela esteve presente 
em ambos os grupos, embora de maneiras diferentes, indicando uma tendência ao exercício de uma sexualidade informada de cunho preventivo. No entanto, outros enunciados mostram que essa racionalidade encontra resistências. Embora não claramente explicitadas, como foram os propósitos preventivos, elas se configuraram como um pano de fundo relativamente estável nos relatos.

Essa contraposição parece corresponder a um conflito básico vivenciado pelos entrevistados, envolvendo a antinomia entre o modo como pensam que devem se comportar (utilizando sempre as tecnologias higiênicas que lhes foram informadas) e o modo como efetivamente se comportam (exercendo frequentemente atividades sexuais sem proteção, como o uso não consistente do preservativo).

$\mathrm{Na}$ discussão que segue, procura-se contribuir com alguns elementos interpretativos sobre essa contraposição fundamental.

\section{Roteiro intrapsíquico “informado" e "normatizado"}

Como se vê nos resultados, embora os elementos da amostra tenham alegado dificuldades para falar sobre o tema proposto, encontraram com relativa rapidez um caminho expressivo para a interlocução, marcado por um padrão racional e prescritivo de fala (“Tem que..."), mote de algumas exposições longas.

Embora essa elaboração discursiva "normatizadora" e "informada" possa ter sido influenciada pela qualidade da questão disparadora proposta, considerase que os participantes foram além de simplesmente reverberar o slogan da campanha ministerial. Os participantes do grupo I repeliram ativamente em suas falas quaisquer elementos ideativos referentes a uma sexualidade anômica, sem normas e valores claros a serem seguidos. Ao contrário, deixaram claros quais os limites de seus roteiros intrapsíquicos: devem estar contidos na racionalidade das normas e regras previstas no modelo de uma sexualidade preventiva amparada por saberes biomédicos.

Há em suas falas cadências expressivas assertivas, como se eles se referissem a obviedades: as pessoas não aderem às tecnologias higiênicas somente no caso de falta de informaçôes, referidas como subsídios necessários para quaisquer pensamentos sobre práticas sexuais, como uma commodity necessária a qualquer desempenho. Constatou-se mesmo uma clara postura etnocêntrica relacionada aos "outros", aos que supostamente não utilizam as informaçôes, identificados como de uma subcultura distinta e a um estrato socioeducacional inferior. 
Consideraram que a qualidade dessa commodity é garantida se corresponder ao corpo de conhecimentos biomédicos técnico-científicos, adquirido pelas práticas de educação formal em saúde sexual. Práticas informais - por exemplo, na convivência social espontânea com os pares - não foram citadas no grupo I.

Para esses entrevistados, as práticas sexuais corresponderiam a um risco da modernidade, dependente direta e exclusivamente dos órgãos sensoriais das ciências para serem avaliados (BECK, 2010). Mas o fato de valorizarem as informações como um recurso para exercerem suas sexualidades não significa um acesso ao universo semântico científico, potencialmente gerador de dissonâncias e sobrecargas emocionais (BECK, 2010), havendo no corpus vários percalços no emprego de conceitos científicos.

Tais ameças modernas - no presente caso, sobretudo a contaminação pelo HIV - não se associam apenas a explicações teóricas de uma minoria de profissionais da ciência que entende mais claramente as suposiçōes científicas causais em jogo: cercam-se também de componentes normativos sobre como as pessoas devem se comportar diante de tais ameaças. Assim, as normas prescritivas das campanhas da "luta contra a Aids" parecem ter sido mais facilmente assimiladas do que as suposições teóricas subjacentes.

\section{Conflito “informação versus prazer”}

Consideram-se presentes no corpus dois tipos de oposições, ambos envolvendo a sobrevalorização da commodity informação. Os componentes da primeira oposição ocorrem internamente à esfera de roteirização intrapsíquica (GAGNON, 2006; BOZON, 2009), opondo elementos cognitivos aos elementos da ordem dos impulsos sexuais.

As falas prescritivas praticamente ubíquas e a redundância da ideia de "ter que" (usar camisinha, proteger-se, cuidar-se, etc.) contrastam com a relativa ausência de menções ao prazer sexual proporcionado pelo sexo sem preservativo. Há na literatura, porém, indícios de que a busca desse prazer seja um fator de resistência ao uso do preservativo pelos adolescentes (SEOANE PASCUAL, 2002). Como não se presume que essa dimensão (desejo e prazer) esteja ausente dos roteiros intrapsíquicos, ela pode ter sido apenas psicologicamente negada durante os depoimentos. Não se supõe ter havido fortes constrangimentos, à medida que os entrevistadores eram do mesmo sexo e faixa etária dos entrevistados: houve, sim, 
uma ausência quase total de valorização explícita e uso de termos designativos da fruição de prazer sexual, constatada a partir de uma busca ativa nos corpora sobre termos correlatos a prazer, excitação ou desejo. Estando certamente presentes em seus imaginários, embora não comunicadas, as representações de desejo e prazer permanecem emudecidas nos enunciados, em consonância com sua não explicitação no cenário mais amplo que compõe os roteiros sexuais em sua dimensão cultural (GAGNON, 2006), de onde emergem as campanhas preventivas da Aids. Como condições pessoais/individuais, desejo e prazer persistiriam contrapostos às clássicas e ainda hegemônicas abordagens preventivas prescritivas baseadas na epidemiologia comportamental (PAIVA, 2008).

\section{Conflito "informação versus habitus"}

A segunda oposição constatada se dá entre elementos dos roteiros sexuais intrapsíquicos adotados conscientemente pelos entrevistados e os componentes dos roteiros interpessoais de fato cumpridos por eles. Se os roteiros intrapsíquicos foram altamente influenciados pelas mensagens institucionais informativas, os roteiros interpessoais parecem refletir (decisivamente, ao que tudo indica) algumas permanências culturais estruturadas conformes a um habitus masculino mais tradicional.

Especialmente no grupo II, foram valorizados padrões de aquisição de subsídios para a conduta sexual fora da educação formal, fundamentados na noção de maturação individual e de contatos sociais com pessoas próximas. Talvez a busca de um aprendizado tácito ocorra em parte para compensar as dificuldades de apreensão cognitiva de objetos científicos associados às tecnologias higiênicas. Além disso, pode representar também a atuação de permanências psicoculturais ligadas à identidade "apropriada" ao papel de homem. Os homens tradicionalmente adquirem um padrão comportamental de ser homem e de como praticar sexo a partir da observação, convivência e do aprendizado com outros homens já iniciados aos padróes de socialização masculina (WELZER-LANG, 2001). Utilizando a análise de Louis Pinto acerca do pensamento de Bourdieu (PINTO, 2000), as falas dos dois grupos expressariam uma dimensão categorial de gênero no que se refere à sexualidade, pois, ao apontá-la como "complexa" e "difícil" para os homens (tal como exposto na seção "resultados"), estariam reafirmando a demarcação de alguns aspectos que concorrem para a operação de 
um habitus masculino diferente e oposto ao feminino. Esses aspectos se relacionam

talvez à divisão de trabalho e às características dos gêneros, cabendo às mulheres os cuidados com o corpo, dada sua "natural" propensão a observarem, estarem atentas e vigilantes (BOURDIEU, 2002).

\section{Conclusão}

A base empírica sobre a qual se trabalhou corrobora a ideia de ainda haver nítidas limitações na efetividade das iniciativas oficiais de educação em saúde baseadas em informações sobre práticas sexuais de risco, pelo menos em alguns grupos populacionais. A premissa de que se partiu, referente à complexidade dos fatores que fundamentam os discursos e práticas sexuais quanto aos cuidados preventivos, pode ser considerada ratificada. Foi chamativo um possível efeito "perturbador" da dimensão prazer, certamente presente no imaginário dos entrevistados mas pouco enfatizado em seus enunciados, assim como nas práticas educativas formais em saúde sexual. No mesmo sentido, os atualmente prevalentes roteiros sexuais intrapsíquicos "informados" ou "instruídos” parecem se contrapor a práticas ou roteiros "formados" segundo roteiros sexuais culturais mais estáveis, provável parte do habitus masculino. Foram chamativas as menções às trocas informais de informações e de experiências entre os jovens do sexo masculino e menções que parecem expressar uma categorização de gênero, ao afirmarem ser particularmente difícil para os homens expressar-se sobre sexualidade e cuidados sexuais. A forte herança cultural da qual os homens são detentores parece funcionar como um amortecedor do impacto de um roteiro intrapsíquico "instruído" e pode, em tese, manter os comportamentos ditos de risco. Isso é observável tanto em termos populacionais - como pesquisas epidemiológicas sobre comportamento sexual e percepção "de risco" - quanto em narrativas referentes a biografias específicas, caso da presente pesquisa.

A dissonância entre os roteiros intrapsíquicos e os roteiros interpessoais e culturais inferidos a partir dos relatos sugere haver, no mínimo, uma demora considerável para que os elementos cognitivos "passem" para as outras instâncias de roteirização sexual, sendo a dimensão cultural, por definição, certamente a mais refratária a mudanças contingenciais representadas pelas informações em saúde.

Parte das inferências feitas aqui se deram a partir das dificuldades dos entrevistados de se expressar sobre suas vivências. Não se pode desconsiderar que 
esses rapazes estavam diante de um entrevistador que, a despeito de ser da mesma faixa etária e sexo, talvez representasse a análise e os conhecimentos acadêmicos, dificultando, talvez, suas falas.

Como em qualquer pesquisa qualitativa, a validade externa dos achados discutidos não decorre das características amostrais, devendo a plausibilidade das interpretaçôes feitas ser avaliada diante de contextos específicos. ${ }^{1}$

\section{Referências}

ANTUNES, M.C.; STALL, R.D.; PAIVA, V. et al. Evaluating an Aids sexual risk reduction program for young adults in public night schools in São Paulo, Brazil. Aids, v.11 Supl 1, p.S121-127, 1997.

BARDIN, L. Análise de conteúdo. Lisboa: Edições 70, 1979.

BECK, U. Sociedade de risco. São Paulo: Ed. 34, 2010.

BERQUÓ, E.; BARBOSA, R.M.; LIMA, L.P.D. Uso do preservativo: tendências entre 1998 e 2005 na população brasileira. Rev Saúde Pública, v.42, p.34-44, 2008.

BOURDIEU, P. A dominação masculina. (1998). 2 ed. Rio de Janeiro: Bertrand Brasil, 2002. . Meditaçôes pascalianas. (1997). 2 ed. Rio de Janeiro: Bertrand Brasil, 2007.

BOZON, Michel. Sociologie de la sexualité. 2 ed. Paris: Armand Colin, 2009.

BRASIL. MINISTÉRIO DA SAÚDE. Dia Mundial 2007 - Sua atitude tem muita força na luta contra a Aids. Brasília, 2007. Disponível em: <http://www2.aids.gov.br/data/Pages/ LUMISC00B1070ITEMID4460B47795444E3789B93E0929A4E2CBPTBRIE.htm>. Acesso em: 13 out 2010.

BURY, M. Illness narratives: fact or fiction? Sociol Health Illn, v.23, n.3, p.263-285, 2001.

CAMARGO, B.V.; BOTELHO, L.J. Aids, sexualidade e atitudes de adolescentes sobre proteção contra o HIV. Rev Saúde Pública, v.41, p.61-68, 2007.

DENZIN, N.K.; LINCOLN, Y.S. Introduction: the discipline and practice of qualitative research. In: - Handbook of qualitative research. London: Sage Publications, 2000. p.1-29.

DOMINGUES, J.M. Gerações, modernidade e subjetividade coletiva. Tempo soc, v.14, p.67-89, 2002.

FERNANDES, J.C. Evolução dos conhecimentos, atitudes e práticas relativas ao HIV/Aids em uma população de favela do Rio de Janeiro. Cad Saúde Pública, v.14, n.3, p.575-581, 1998. FONTANELLA, B.J.B.; RICAS, J.; TURATO, E.R. Amostragem por saturação em pesquisas qualitativas em saúde: contribuições teóricas. Cad Saúde Pública, v.24, p.17-27, 2008. 
GAGNON, J.H. Uma interpretação do desejo: ensaios sobre o estudo da sexualidade. Rio de Janeiro: Garamond, 2006.

HERZLICH, C. Saúde e doença no início do século XXI: entre a experiência privada e a esfera pública. Physis - Revista de Saúde Coletiva. Rio de Janeiro, v.14, n.2, p.383-394, 2004. HYDÉN, L. Illness and narrative. Sociol Health Illn, v.19, n.1, p.48-69, 1997.

JOVCHELOVITCH, S.; BAUER, M. W. Entrevista narrativa. In: BAUER M. W.; GASKELL G. (Orgs.); Pesquisa qualitativa com texto, imagem e som: um manual prático. Petrópolis: Vozes, 2002. p.90-113.

MINAYO, M.C.S. O desafio do conhecimento: pesquisa qualitativa em saúde. São Paulo: Hucitec, 2007.

PAIVA, V. A psicologia redescobrirá a sexualidade? Psicol estud, v.13, n.4, p.641-65,2008.

PINTO, J.A.; RUFF, A.J.; PAIVA, J.V. et al. HIV risk behavior and medical status of underprivileged youths in Belo Horizonte, Brazil. J Adolesc Health, v.15, n.2, p.179-185, 1994.

PINTO, L. Pierre Bourdieu e a teoria do mundo social. Rio de Janeiro: FGV, 2000.

SEOANE PASCUAL, L. Evaluación cualitativa de una campaña de promoción del uso del preservativo en la población adolescente y juvenil de la Comunidad de Madrid. Revista Española de Salud Pública, v. 76, n. 5, 2002. Disponível em: <http://www.scielosp.org/ scielo.php?pid=S1135-57272002000500012\&script=sci_abstract\&tlng=enen $>$. Acesso em: 17 out 2010 .

TRAJMAN, A.; BELO, M.T.; TEIXEIRA, E.G. et al. Knowledge about STD/Aids and sexual behavior among high school students in Rio de Janeiro, Brazil. Cad Saúde Pública, v.19, p.127-133, 2003.

VAITSMAN, J. Flexíveis e plurais: identidade, casamento e família em circunstâncias pósmodernas. Rio de Janeiro: Rocco, 1994.

VELHO, G. Individualismo e cultura. Rio de Janeiro: Zahar, 1981.

WELZER-LANG, D. A construção do masculino: dominação das mulheres e homofobia. Rev Est Fem, v.9, p.460-482, 2001.

\section{Nota}

${ }^{1}$ B.J.B. Fontanella realizou a análise, interpretação e discussão dos resultados aqui abordados e redigiu o artigo. R. Gomes elaborou o projeto de pesquisa, supervisionou a coleta de dados, participou da análise e interpretação dos resultados e da redação final do artigo. 


\section{Abstract}

\section{New intra-psychic scripts versus cultural continuities: possible limits of an informed sexuality}

This paper aimed to analyze the meanings attributed by young men to male sexuality and sexual practices in order to understand any difficulties in adhering to preventive practices in relation to AIDS. Based on the theory of sexual scripts and the concept of habitus, we performed a discourse analysis on a collection of 42 stories, from their youth subsamples differentiated in terms of education and socioeconomic status. Two conflicts seem to influence crucial preventive sexual practices of participants. On the one hand, cognitive elements of a "sexuality informed" oppose the dimension of pleasure related to sexual practices; on the other, these information elements are opposed to the more stable components related to psycho male habitus. The empirical basis on which it worked allows a deeper understanding of the clear limitations of the effectiveness of prevention initiatives in health based on information about risky sexual practices.

Key words: gender and health; sexuality; gender identity; narrative; qualitative research. 